\title{
Assessing the spatiotemporal changes in China's core supply and supporting ecosystem services
}

\author{
xiaoyong Bai ${ }^{1}$ \\ ${ }^{1}$ Institute of Geochemistry Chinese Academy of Sciences
}

May 5, 2020

\begin{abstract}
The supply of ecosystem services (ES) is critical to sustaining human livelihoods, and understanding their driving mechanisms and impacts can contribute to sustainable ecological management. This paper aims to reveal the spatiotemporal changes and dynamics of ES in China from 1992 to 2015.SC (Soil conservation), WY (Water yield), NPP (Net primary productivity) and FS (Food supply) are selected for evaluation. The ability of ES to provide is increasing; the area where ES synergy is more dominant accounts for about half of the total land area, and ecological restoration here has a very high added value; in addition, we do not think that we cannot blindly pursue forest coverage during the ecological restoration The specific case is that afforestation activities in the Loess Plateau and Continental basin have exacerbated water shortages. It is the practical significance of this paper to clarify and reverse the regional ES trade-off relationship to achieve sustainable development.
\end{abstract}

\section{Hosted file}

Assessing the spatiotemporal changes in China's core supply and supporting ecosystem services.pdf available at https://authorea.com/users/289198/articles/415073-assessing-the-spatiotemporalchanges-in-china-s-core-supply-and-supporting-ecosystem-services 